\title{
Role for Dopamine Neurons of the Rostral Linear Nucleus and Periaqueductal Gray in the Rewarding and Sensitizing Properties of Heroin
}

\author{
Juan A Flores', Beatriz Galan-Rodriguez', Susana Ramiro-Fuentes' and Emilio Fernandez-Espejo*,' \\ 'Departamento de Fisiologia Medica y Biofisica, Universidad de Sevilla, Sevilla, Spain
}

\begin{abstract}
There is a mesencephalic dopaminergic network outside the ventral tegmental area (VTA), including structures such as the rostral linear nucleus (RLi) and periaqueductal gray (PAG). These nuclei project to neural areas implicated in reinforcing effects of drugs, indicating that they could participate in opiate reward. The objectives were to study the morphological characteristics of the dopamine network of the RLi/PAG region, and to discern its role on rewarding and sensitizing effects of heroin in rats, following dopamine depletion or local injection of dopaminergic antagonists. The findings indicated that this network is composed of small cells in the RLi/ventral PAG, large multipolar dopamine PAG neurons, and periaqueductal PAG neurons. Following repeated heroin, large PAG neurons and small RLi/ ventral PAG cells (not periaqueductal neurons) were activated, since tyrosine-hydroxylase was adaptively induced, without changes in protein kinase A $\alpha$. After dopamine depletion, small RLi/ventral PAG neurons and large cells of the PAG (not periaqueductal ones) were selectively affected by the neurotoxin. Dopamine neurons of the nearby VTA and dorsal raphe were not affected, as revealed by cell counting. After lesion, 'anxiety-like' responses and basal locomotion were not altered. However, conditioned place preference to heroin was found to be abolished, as well as heroin-induced motor sensitization. Following infusions of dopaminergic antagonists into RLi/PAG, $D_{2}$ (not $D_{1}$ ) receptor blocking dose-dependently abolished heroin-induced reward. The present study provides evidence that dopamine neurons of the RLi/PAG region (excluding PAG periaqueductal cells) show adaptive biochemical changes after heroin, and mediate the rewarding and sensitizing effects of this drug. $D_{2}$ dopamine receptors within the RLi/PAG region participate in these effects.

Neuropsychopharmacology (2006) 31, | 475-| 488. doi: 1 0. I 038/s.npp. I 300946; published online 9 November 2005
\end{abstract}

Keywords: heroin; reward; sensitization; dopamine; periaqueductal

\section{INTRODUCTION}

There is a continuous network of dopaminergic neurons that extends throughout the mesencephalon, including neurons within the ventral tegmental area (VTA, A10 area), the rostral linear nucleus (RLi), the periaqueductal gray (PAG), and dorsal raphe (DR). The PAG/DR network is also termed the dorsocaudal A10 group (A10dc) (Hökfelt et al, 1984; Hasue and Shammah-Lagnado, 2002). Figure 1 shows representative mesencephalic sections including those nuclei with dopaminergic neurons. The VTA is considered as a critical region for rewarding properties of drugs of abuse, but the role of adjacent dopaminergic areas is not well known.

\footnotetext{
*Correspondence: Dr E Fernandez-Espejo, Departamento de Fisiologia Medica y Biofisica, Universidad de Sevilla, Av. Sanchez Pizjuan 4, E-4 009 Sevilla, Spain, Tel: + 34 954556584, Fax: + 34 95455।769, E-mail: efespejo@us.es

Received 17 February 2005; revised 7 September 2005; accepted 14 September 2005

Online publication: 21 September 2005 at http://www.acnp.org/ citations/Npp092 105050 I09/default.pdf
}

The RLi nucleus is composed of small and rounded dopamine neurons, and is considered as independent to the VTA (Phillipson, 1979) although some authors incorporate it to this area (Oades and Halliday, 1987). The dopaminergic network of the PAG is composed of small and large neurons (Hasue and Shammah-Lagnado, 2002). Dopamine neurons of the RLi/PAG region project locally or onto different brain structures such as the central amygdaloid nucleus, bed nucleus of the stria terminalis, sublenticular extended amygdala, and substantia innominata (Ottersen, 1981; Grove, 1988; Hasue and Shammah-Lagnado, 2002). These neural areas are of relevance for drug reward, particularly the central amygdaloid nucleus and extended amygdala (Wise, 1989; Caine et al, 1995; Di Chiara et al, 1999; Nestler, 2001). Considering these connections and the key role of dopamine on drug reward, RLi and PAG could participate in opiate reward. Besides, the number of amygdalopetal dopaminergic fibers arising from the PAG (and DR) is the same that those arising from A8, A9, and VTA-A10 groups together (Hasue and Shammah-Lagnado, 2002), and RLi/ PAG tyrosine hydroxylase TH + efferents course in the VTA and medial forebrain bundle (MFB) suggesting that they 

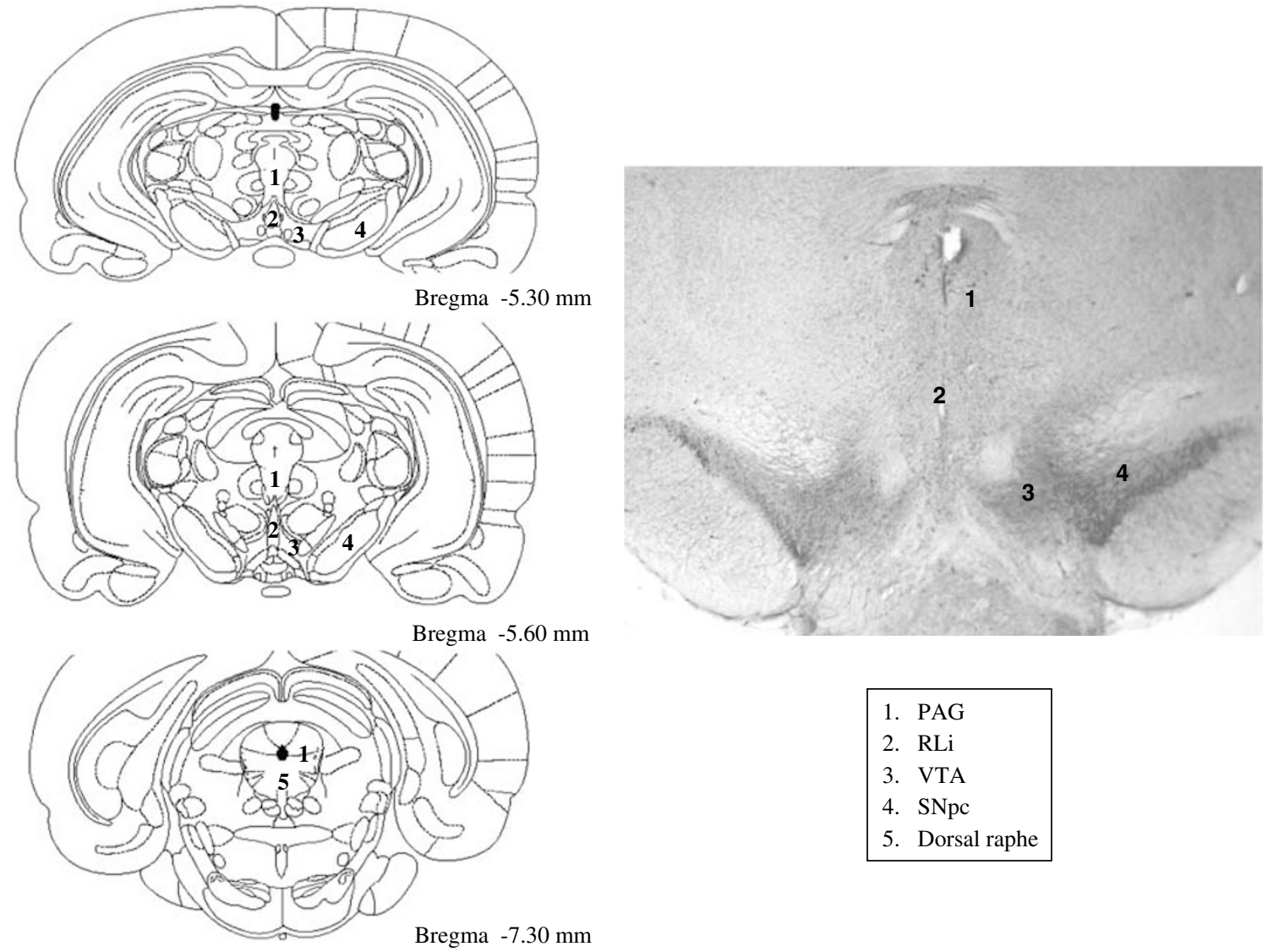

Figure I Left column: Pictures of mesencephalic sections taken from the Paxinos and Watson's atlas (1997) showing main mesencephalic nuclei containing dopaminergic neurons. Right column: Micrographs of a representative mesencephalic section after TH immunohistochemistry, showing mesencephalic nuclei with dopaminergic neurons. PAG, periaqueductal gray; RLi, rostral linear nucleus; VTA, tegmental ventral area (AI0); SNpc, substantia nigra pars compacta.

could also be affected after VTA and MFB dopaminergic lesions and participate in functional changes reported by different authors (Vertes, 1991).

Addictive effects of opiates can be evaluated through either conditioned place preference (CPP, an index of the incentive value of the drug) or locomotor sensitization. The latter is the enhancement in the motor stimulant effects elicited by repeated drug administration (Stewart and Badiani, 1993; Vanderschuren and Kalivas, 2000; Nestler, 2001), and neural and biochemical adaptations that result in sensitization in animal models are likely the same which result in some forms of addictive behavior in humans (Robinson and Berridge, 1993; Carlezon et al, 1997; Nestler and Aghajanian, 1997; Messer et al, 2000; Nestler, 2001). It is widely accepted that repeated opiate exposure is linked to biochemical traits in several mesolimbic regions, such as increase of TH in the VTA or protein kinase $\mathrm{A} \alpha(\mathrm{PKA} \alpha)$ upregulation in the nucleus accumbens (Terwilliger et al, 1991; Beitner-Johnson and Nestler, 1991; Self et al, 1995; Brodkin et al, 1999). TH upregulation seems to be linked to augmented dopamine neurotransmission in the VTA and terminal regions such as the nucleus accumbens (BeitnerJohnson and Nestler, 1991; Sklair-Tavron et al, 1996), and heightened dopaminergic neurotransmission is thought to trigger the induction of transient immediate early genes, and more enduring transcription factors implicated in morphine's motor sensitization and reward (Nye and Nestler, 1996; Segal and Kuczenski, 1992; Self and Nestler, 1995). Activation of accumbal PKA has been shown to be critical for the motor-sensitizing effects of drugs of abuse (Cunningham and Kelley, 1993; Miserendino and Nestler, 1995). These biochemical changes could also take place in the RLi/PAG region after opiates. The objectives of this study were: (i) to further describe the morphological characteristics of the dopaminergic network extended throughout the RLi/PAG region, (ii) to discern if these dopaminergic cells are activated after repeated heroin administration (as measured through $\mathrm{TH}$ and PKA $\alpha$ expression), (iii) to establish the effects of selective lesions of the DA neurons of RLi/ PAG region on heroin-induced reward (as measured through CPP) and locomotor sensitization, and (iv) to discern the role of $D_{1}$ and $D_{2}$ dopamine receptors within RLi/PAG on heroin-mediated effects.

\section{MATERIALS AND METHODS}

\section{Animals and Experimental Protocol}

Male Wistar rats (275-325g) from the breeding colony of the Faculty of Medicine of the University of Seville, Spain, were used. Laboratory temperature was kept at $22 \pm 1^{\circ} \mathrm{C}$, and a 12-h light-dark cycle (lights on at $0800 \mathrm{~h}$ ) was 
maintained throughout the experiment. Food (lab chow) and water were available ad libitum. Four experiments were carried out: (1) morphological study of the dopaminergic network of the RLi/PAG region; (2) adaptive biochemical changes in dopamine neurons of the RLi/PAG region after repeated heroin, (3) dopamine depletion of the RLi/PAG region, corresponding morphological changes, and effects of lesion on basal motor and emotional responses as well as heroin-induced reward and sensitization, and (4) intra-RLi/ PAG injections of dopaminergic antagonists and their effects on heroin-induced reward. For experiment 1,10 rats were used. For experiment 2, 24 rats were used $(n=12$ for immunolabelling for TH, $n=12$ for studying $\mathrm{TH}$ and PKA $\alpha$ blotting signals). For experiment 3, 56 rats were used ( $n=28$ sham rats, $n=28$ lesioned rats). For experiment 4 , 42 rats were used ( $n=21$ for $\mathrm{D}_{1}$ dopamine receptor effects, $n=21$ for $\mathrm{D}_{2}$ dopamine receptor effects), and another group of 10 rats was used for extra-RLi/PAG injections. The opiate heroin sulfate was used (RBI, USA), the drug being dissolved in double-distilled water. For experiment 4, two dopamine receptor ligands, SCH $23390\left(\mathrm{D}_{1}\right.$ dopamine receptor antagonist, Tocris) and eticlopride $\left(\mathrm{D}_{2}\right.$ dopamine receptor antagonist, RBI, USA), were used. Experiments were performed according to the animal care guidelines of the European Communities Council (86/609/EEC).

\section{Experiment 1}

The morphology of the dopaminergic network of the RLi/ PAG region was studied in normal rats.

Immunohistochemistry and immunofluorescence. Naïve rats were killed by decapitation and brains carefully removed $(n=10)$. After dissection, brains were stored in $4 \%$ paraformaldehyde in phosphate buffer (PB) $0.1 \mathrm{M}(\mathrm{pH}$ 7.2-7.4) at $4{ }^{\circ} \mathrm{C}$, and later immersed overnight in $25 \%$ sucrose in PBS for cryoprotection before sectioning. Coronal brain sections ( $30 \mu \mathrm{m}$ thick) were cut on a cryostat and collected in PBS. Thereafter, endogenous peroxidase activity was quenched by placing sections into $0.3 \% \mathrm{H}_{2} \mathrm{O}_{2}$ in 0.05 Tris buffer $(\mathrm{pH}=7.6)$ for $2 \mathrm{~h}$. Then sections were incubated in PBS $/ 0.1 \%$ Triton X-100 (PBS-T) with $10 \%$ FCS (Vector, USA) and BSA ( $1 \mathrm{mg} / \mathrm{mgl}$, Sigma, USA) for $4 \mathrm{~h}$ to block nonspecific binding sites. Sections were incubated overnight with mouse anti-tyrosine-hydroxylase (TH) monoclonal antibody (anti-TH, 1:1000, Sigma, USA) and rabbit anti-dopamine- $\beta$-hydroxylase (DBH) antibody $(1: 1000$, Diasorin, Spain) in PBS-T, and, after washing in PBS-T, they were incubated for $10 \mathrm{~h}$ with anti-mouse or anti-rabbit biotin-conjugated antibody $(1: 200$, Chemicon, USA). Then, sections were incubated with the $A B C$ kit ( $1: 100$, Pierce, USA) for $2 \mathrm{~h}$, and specifically bound antibody was revealed by using 3.3'-diaminobencidine tetrahydrochloride (DAB, Sigma, USA) as chromogen, and $0.05 \%$ hydrogen peroxide (Merck). Control sections were incubated in the same solutions for the same incubation times as the other brain sections, with the exception that the primary antibody solution was replaced by a PBS-T solution containing $10 \%$ FCS and BSA $(1 \mathrm{mg} / \mathrm{ml})$ without the primary antibody. Sections were washed in PBS and mounted on glass slides and coverslipped with DPX. For immunofluorescence, sections were incubated overnight with rabbit anti-TH $(1: 1000$, Chemicon, USA), and mouse anti-NeuN monoclonal antibody ( $1: 1000$, Chemicon, Spain) in PBS-T, and, after washing in PBS-T, they were incubated for $10 \mathrm{~h}$ with anti-mouse fluorescein-conjugated $(1: 500$, Pierce, USA) and anti-rabbit rhodamine-conjugated antibody $(1: 1000$, Pierce, USA). Sections were washed in PBS and mounted on glass slides and coverslipped with $50 \%$ glycerol $/ 50 \%$ PBS.

Stereological methods. Volumetric measurements were carried out by applying the principle of Cavalieri, using photo sections (Lagares and Avendaño, 1999). Every five coronal sections $(50 \mu \mathrm{m}$ width, $\bar{t}=200 \mu \mathrm{m})$ of the mesencephalus including the VTA and the RLi/PAG region were randomly sampled by using a reticle of hitting points, where the area associated with each sampling point was $0.11 \mathrm{~mm}^{3}(a(p))$. The estimate of the volume was calculated as $V=\bar{t} \cdot a(p) . \Sigma \mathrm{Pi}$, where $\Sigma \mathrm{Pi}=$ total number of hitting points. The coefficient of error was calculated according to a formula which takes into account the shape of the organ (e.g. 3.8 for an irregular prismatic-like structure such as the RLi/PAG region; Gundersen and Jensen, 1987). The number of $\mathrm{TH}+$ cells was calculated applying the physical disector method (Sterio, 1984). For this procedure, six systematically chosen pairs of adjacent sections $(\bar{t}=200 \mu \mathrm{m})$ were used. Four disector frames were used for every section, and the area of the disector frame covered $16,104 \mu \mathrm{m}^{2}(a(\mathrm{ret}))$. The estimated disector volume or $\Sigma V($ dis $)$ was calculated as $\Sigma V($ dis $)=$ number of disectors $\bar{t}$. a(ret). The estimate of the number of cells $(N)$ was calculated as $N=\left(\Sigma Q^{-} . V(\right.$ ref $\left.)\right) / \Sigma v($ dis $)$, where $\Sigma Q^{-}$was the total number of cells counted in all the disectors, and $V(\mathrm{ref})$ was the estimate of the volume of the studied region, as measured by the principle of Cavalieri.

\section{Experiment 2}

Saline or heroin were administered daily during 3 days (heroin, $500 \mu \mathrm{g} / \mathrm{kg}$ s.c.). Rats were killed $2 \mathrm{~h}$ after the last heroin administration, for studying TH and PKA $\alpha$ expression in the RLi/PAG region, both known markers for biochemical adaptations to opiates.

Immunohistochemistry and measurement of $\mathrm{TH}+\mathrm{neu-}$ ronal density in the $R L i / P A G$ region. Immunohistochemistry was performed as explained before (saline, $n=6$; heroin, $n=6$ ). The optical density of $\mathrm{TH}+$ large and small neurons of the RLi/PAG region was measured at four different rostrocaudal levels corresponding to -5 , $-5.3,-5.6$, and $-6 \mathrm{~mm}$ relative to bregma (Paxinos and Watson, 1997). Images of coronal sections were taken with a high-resolution digital camera from a microscope equipped with a natural density filter to give constant illumination throughout the specimen. The digitalized images were analyzed using Scion Image for PC. Optical density readings were corrected for background staining (commissure superior colliculi, a nondopaminergic region of the tissue). All values are expressed as percent of the background staining for each section.

Western blotting. Brains were removed from decapitated rats (saline, $n=6$; heroin, $n=6$ ) and cooled in ice-cold 
physiological buffer. The RLi/PAG region was obtained by careful dissection of the region under microscope observation, according to the Paxinos and Watson's atlas (1997). Brain samples were lysated in $10 \%$ glycerol, $137 \mathrm{mM} \mathrm{NaCl}$, and $20 \mathrm{mM}$ Tris $\mathrm{HCl}, \mathrm{pH} 7.5$, containing peptidases $(1 \mu \mathrm{g} / \mathrm{ml}$ aproteinin and leupeptin, $1 \mathrm{mM}$ PMSF). Protein levels were quantified by using the Bradford method. Samples were boiled and aliquots containing $25 \mu \mathrm{g}$ of protein each were subjected to SDS/polyacrylamide gel electrophoresis. Proteins were transferred electrophoretically to PVDF membranes, which were the blocked with $2 \%$ nonfat dry milk in TTBS, pH 7.5 (5 M NaCl, 2\% $1 \mathrm{M}$ Tris-HCL, 0.05\% Tween 20). Immunolabelling was conducted for $\mathrm{TH}$ with mouse monoclonal anti-TH antibody $(1: 1000$, Sigma), PKA $\alpha$ with rabbit polyclonal anti-PKA $\alpha$ antibody (Santa Cruz, USA), and $\alpha$-tubulin (control protein) with mouse monoclonal anti- $\alpha$-tubulin antibody (Santa Cruz). Primary antibodies were detected with peroxidase-linked secondary antibodies (Santa Cruz) and with enhanced chemiluminescence (ECL) (Amersham, USA), and autoradiography. Band densities of resulting autoradiograms were quantified by using the Scion Image for PC (NIH, USA).

Statistics. Density values of $\mathrm{TH}+$ immunosignal and of blot bands were compared with the nonparametric MannWhitney $U$-test.

\section{Experiment 3}

The effects of 6-hydroxydopamine (6-OHDA)-induced lesion of the RLi/PAG region on heroin's CPP and motor sensitization were studied. Possible behavioral deficits ('anxiety-like' and locomotor responses) resulting from 6OHDA-induced lesion of the RLi/PAG were also studied.

6-hydroxydopamine-induced lesion of the RLi/PAG region. At $30 \mathrm{~min}$ before 6-OHDA (RBI) lesion, rats were injected with the antibiotic ceftriazone $(10 \mathrm{mg} / 0.3 \mathrm{ml}$ i.m. $)$, as well as with desipramine $(15 \mathrm{mg} / \mathrm{kg}$ i.p.) and citalopram $(2 \mathrm{mg} / \mathrm{kg}$ i.p. $)$ in order to protect noradrenergic and serotonergic fibers from 6-OHDA toxicity, respectively. Rats were anesthetized with ketamine $(50 \mathrm{mg} / \mathrm{kg}$ i.m.) and xylazine $(10 \mathrm{mg} / \mathrm{kg}$ i.m.), and placed in a Kopf stereotaxic apparatus with the incisor bar set $3.3 \mathrm{~mm}$ below the interaural line. Saline solution $(0.3 \mu \mathrm{l}$ per site) containing 6 -OHDA $(5 \mu \mathrm{g} / \mu \mathrm{l})$ and $0.2 \%$ ascorbic acid was injected over 5 min with a blunted 30-gauge cannula at the following coordinates with respect to bregma: $\mathrm{AP}=-5.6, L= \pm 0.5$, and $V=-5.5$ (Paxinos and Watson, 1997). The cannula was left in place for $1 \mathrm{~min}$ after injection. Control rats followed the same protocol, except that a 6-OHDA-free solution $(0.9 \% \mathrm{NaCl}$ and $0.2 \%$ ascorbic acid) was injected. Rats were allowed 1 week to recover after surgery before experimental tests began.

'Anxiety-like' and open-field tests. In order to address whether there are behavioral deficits resulting from 6-OHDA-induced lesion of the RLi/PAG that could mask or interfere CPP and motor sensitization results, 'anxietylike' and basal locomotor responses were studied in all lesioned and sham rats ( $n=28$ each group). 'Anxiety-like' behaviors were analyzed by using the light-dark and elevated plus-maze tests, two animal models of anxiety. The light-dark apparatus consisted of a two-compartment rectangular box made up of Plexiglas, with one compartment painted white $(30 \times 48 \times 34 \mathrm{~cm}$ high $)$ and illuminated by a $60-W$ white incandescent bulb (900 lux) and the other compartment painted black $(30 \times 48 \times 34 \mathrm{~cm}$ high $)$, without illumination. The two compartments were connected by an opening $(9 \times 8 \mathrm{~cm})$. Rats were placed in the light compartment at the beginning of the test, and several behavioral parameters were quantified over $5 \mathrm{~min}$ : time spent in light compartment, time spent in dark compartment, and number of transitions from dark to light (Espejo and Miñano, 1999). Operational criterion for entry was whole body and four paws entry. Time spent in light and number of transitions from dark to light are negative indicators of anxiety, to say, the higher their values the lower anxiety-like level. Time spent in dark is a positive index. The elevated plus-maze consisted of two open arms $(50 \times 10 \mathrm{~cm})$ and two enclosed arms $50 \times 10 \times 40 \mathrm{~cm}$, arranged such that two pairs of identical arms were opposite to each other. Arms emerged from a central platform $(10 \times 10 \mathrm{~cm})$, and the entire apparatus was raised to a height of $50-\mathrm{cm}$ above the floor level. At the beginning of the test, the rat was placed in the central platform facing an open arm. After each $5 \mathrm{~min}$ test, the maze was carefully cleaned up with a wet towel. Anxiety was evaluated through percent time spent on open arms, percent time spent on closed arms, and number of transitions from closed to open arms. Percent open time and number of transitions from closed to open arm are negative indicators of anxiety, and percent closed time is a positive indicator (Rodgers and Cole, 1994; Espejo, 1997). For each group of rats 'anxiety-like' behavior was studied $30 \mathrm{~min}$ after the administration of saline or the anxiolytic compound diazepam ( $2.5 \mathrm{mg} / \mathrm{kg}$ i.p. $)$, in order to discern the basal 'anxiety-like' level, as well as if both groups of animals responded to an anxiolytic dose of diazepam (Finlay et al, 1995; Wilson et al, 2004). Regarding tests, they were performed daily, and the light-dark test was carried out first. For each anxiety test, saline or diazepam was injected following a Latin-square design (half of the rats were injected with saline the first day of the test, and the other half were injected first with diazepam), in order to minimize the possible learning effects following test repetition. The first anxiety test was carried out 1 week after surgery.

At 2 days after the last elevated plus-maze test, locomotor activity was evaluated. Each rat was placed in an open field $(1 \times 1 \mathrm{~m})$ for $10 \mathrm{~min}$, and distance travelled was quantified. Time spent on each light/dark compartment or closed/open arm as well as distance travelled were measured by using the automatized Smart system (Panlab, Spain). Behavior in the anxiety-like tests was also videotaped, and the number of transitions was scored 'blind' by a trained observer (intra rater reliability $=0.9$ ). All behavioral tests were carried out during the last phase of the light period (1800 to $2000 \mathrm{~h}$ ).

Conditioned place preference. Half of the lesioned $(n=14)$ and sham $(n=14)$ rats were used for this study. The CPP apparatus used to evidence a reliable conditioned preference consisted of three rectangular boxes $(40 \times 33 \times 34 \mathrm{~cm})$ arranged radially $\left(120^{\circ}\right.$ to each other $)$ 
and accessible from a triangular central section (Stinus et al, 1990; Schulteis et al, 1994; Caillé et al, 1999). Distinctive visual and tactile cues distinguished the three compartments: the walls and floor coloring (yellow stripes, red squares and black stripes), and the room spatial cues, maintained in the same orientation every day. The set-up was placed in a sound-attenuated testing room, and illuminated by three $15 \mathrm{~W}$ white lights located $1.5 \mathrm{~m}$ above each compartment. The experimental protocol comprised three distinct phases: a preconditioning phase, a conditioning phase, and a testing phase.

In the preconditioning phase (day 1,1 week after the open-field test), animals were placed in the central section and allowed to freely explore the apparatus for $30 \mathrm{~min}$ $(1800 \mathrm{~s})$. Animals showing strong unconditioned aversion (less than $120 \mathrm{~s}$ of the session time) or preference (more than $1680 \mathrm{~s}$ of the session time) for any compartment were discarded. For each rat, the two compartments with the closest time allotments were chosen. One was randomly chosen to be paired to the opiate drug and the other to the vehicle. The unassigned compartment could be either the most or the least preferred of the three. We checked after assigning the compartments that there were no significant differences between time spent in the drug-paired and the vehicle-paired compartments during the preconditioning phase. This is an important step in the experimental procedure which avoids any preference bias prior to conditioning. In the second phase (conditioning), rats received subcutaneous injection of vehicle saline and heroin on days 2-4 (morning, heroin; evening, saline), immediately prior to being confined for $30 \mathrm{~min}$ to their preselected vehicle-paired or drug-paired compartment, respectively ( $\mathrm{v} /$ w $1 \mathrm{ml} / \mathrm{kg}$ body weight). Heroin was injected at 100 and $500 \mu \mathrm{g} / \mathrm{kg} \mathrm{SC}$ ( $n=7$ each lesion or sham group). The testing phase consisted of two 30-min tests of free exploration of the entire apparatus on day 5 (one test in the morning, another in the evening), and the time spent in each compartment was calculated as the mean of both tests. In order to discard habituation of conditioning after repeated testing, time values of both postconditioning tests were compared. Since an unbiased protocol was used, CPP was calculated as time spent in the heroin-paired compartment compared to time spent in the saline-paired side during postconditioning. The preconditioning and postconditioning sessions were videotaped and later analyzed by using the SMART system for behavioral studies (Panlab, Spain), which allows calculating the exact time spent in each compartment.

Locomotor sensitization. Half of the lesioned $(n=14)$ and sham $(n=14)$ rats were used for this study. Rats were tested on $25 \times 25 \mathrm{~cm}$ cages, all animals receiving heroin $(50$ or $100 \mu \mathrm{g} / \mathrm{kg}$ s.c. daily; $n=7$ in each lesion or sham group) in the same environment, 1 week after the open-field test. Locomotor activity was recorded during $2 \mathrm{~h}$ starting immediately after heroin injection. Distance travelled (m) was measured by using the automatized SMART system. Heroin was injected daily during 5 days (induction phase), as well as at day 12 (expression phase). The first injection was preceded by 2 days of habituation, where rats were placed on the environment during $2 \mathrm{~h}$ without treatment, in order to avoid the effects of novelty on locomotor activity.
Immunohistochemistry, stereology, and statistics. Rats were killed after completion of behavioral study, $2 \mathrm{~h}$ after the last heroin administration. Immunohistochemistry for $\mathrm{TH}$ and stereological methods were performed as explained. The mean number of TH + neurons in the RLi/PAG and VTA regions in sham and lesioned rats were compared with the Student's $t$-test. This test was also employed for statistical comparisons between groups in 'anxiety-like' and open-field tests. For CPP, a three-way ANOVA was used (group and dose, between factors; compartment, within factor). Post-hoc comparisons between groups were carried out by using the Tukey's test. Regarding locomotor sensitization, a three-way ANOVA was used in search for significant interaction effects (day of treatment, within factor; group and heroin dose, between factors). Post-hoc Tukey's test was used for discerning statistical differences. When variance was not homogeneous, data were transformed (square $[\mathrm{x}]$ ) prior to analysis.

\section{Experiment 4}

The effects of local intra-RLi/PAG infusions of dopamine receptor antagonists on heroin's CPP and motor sensitization were studied.

Guide cannula surgery and intracranial injections. To study the intra-RLi/PAG effects of dopaminergic ligands, anesthetized rats were given prophylactic ceftriazone and placed in a Kopf stereotaxic apparatus. A hole was drilled over the injection site, and a 22-gauge stainless steel guide cannula (Small Parts. USA) was aimed $2 \mathrm{~mm}$ above the corresponding infusion site: $\mathrm{AP}=-5.6, L=+2$, and $V=-5.5 \mathrm{~mm} v s$ bregma. The cannula was introduced with an angle of $30^{\circ} \mathrm{vs}$ the vertical axis to avoid the sinus vein to be damaged. The guide cannula was fastened to the skull with stainless steel screws (Small Parts, USA) and dental cement, and was fitted with a 30-gauge stainless steel obturator, protruding $2 \mathrm{~mm}$ out of the tip of the guide cannula (Small Parts). Rats were allowed to recover 1 week after surgery. Injections ( $0.5 \mu \mathrm{l}$ each) were performed in the home cage after removing the obturator cannula, that was replaced by a 30-gauge stainless steel internal cannula (Small Parts, USA) connected to a Hamilton syringe and a delivery pump (Stoelting, Germany). Solutions were slowly injected over $5 \mathrm{~min}$, and then the internal cannula was carefully removed 1 min later and the obturator cannula was replaced.

An additional group of 10 rats received cannulae targeted outside the $\mathrm{RLi} / \mathrm{PAG}$ region $(1.5 \mathrm{~mm}$ distant from the ventrolateral $\mathrm{PAG}$ ), in the central tegmental tract, as an anatomical control group. Thus, the stainless steel guide cannula was aimed $2 \mathrm{~mm}$ above the corresponding infusion site: $\mathrm{AP}=-5.6, L=+2$, and $V=-4.5 \mathrm{~mm} v s$ bregma (at the level of the central tegmental tract, Paxinos and Watson, 1997). The guide cannulae for extra-RLi/PAG region placements made trajectories through the cortex similar to cannulae for RLi/PAG sites. This group of rats served for studying the effects of injections in the dorsal vicinity of the RLi/PAG region in order to discard the emergence of behavioral effects due to diffusion of injected solution. After completion of all the experiments, rats' brains were removed and sectioned. Sections were stained by using 
the Nissl method, and then cannula placements were verified under a microscope, mapped onto a stereotaxic atlas (Paxinos and Watson, 1997), and confirmed to be in the RLi/PAG region or in the central tegmental tract.

CPP and dopaminergic ligands. CPP was carried out as explained. Saline or heroin sulfate $(500 \mu \mathrm{g} / \mathrm{kg})$ was injected s.c. immediately before rats were placed on the corresponding compartment (v/w $1 \mathrm{ml} / \mathrm{kg}$ body weight). Dopaminergic ligands were infused $10 \mathrm{~min}$ before heroin injection. Two dopamine receptor antagonists, SCH $23390\left(\mathrm{D}_{1}\right.$ dopamine receptor antagonist, Tocris) and eticlopride $\left(\mathrm{D}_{2}\right.$ dopamine receptor antagonist, RBI, USA), were used. SCH-23390 was injected at 0,1 , and $2 \mu \mathrm{g} / \mu \mathrm{l}$ doses (free-base, $0,4.6$, and $9.1 \mathrm{nmol}, n=7$ in each dose group), and eticlopride was administered at $0,0.5$, and $1 \mu \mathrm{g} / \mu \mathrm{l}$ doses (free-base, $0,2.6$, and $5.3 \mathrm{nmol}, n=7$-each dose group). SCH 23390 was dissolved in double-distilled water, and eticlopride was dissolved in $30 \%$ ethanol $/ 70 \%$ distilled water. The corresponding vehicle was used for the control group in every treatment.

Statistics. For CPP, two-way ANOVA was used (dopaminergic ligand dose, between factor; compartment, within factor). Post-hoc comparisons between groups were carried out by using the Tukey's test. When variance was not homogeneous, data were transformed (square $[x]$ ) prior to analysis.

\section{RESULTS}

\section{Experiment 1}

Dopamine cells of the $R L i / P A G$ region. Following immunolabelling for $\mathrm{TH}$, the morphological study revealed that, as measured through the principle of Cavalieri, the estimate of the volume of the RLi/PAG region was $0.74 \pm 0.09 \mathrm{~mm}^{3}$ (mean \pm SEM). TH + neurons were found to be scattered throughout the RLi and ventrolateral PAG (Figure 2). Detailed microscopical observation of $\mathrm{TH}+$ cells allowed classifying them into three groups depending on their size and location, as observed in Figure 2a-f: (i) small rounded neurons $(10 \mu \mathrm{m}$ in diameter) scattered throughout the ventral PAG and RLi nucleus, where no boundaries between both nuclei could be observed and hence they are referred to as neurons of the RLi/vPAG (Figure 2a,b, and e); (ii) large size cells of the PAG $(30-50 \mu \mathrm{m}$ in diameter) located in the ventrolateral region of the PAG, with a multipolar morphology, and giving rise to abundant fibers with regularly spaced varicosities (Figure 2a-d); and (iii) periaqueductal neurons of the PAG: rounded neurons of diameter $15 \mu \mathrm{m}$ located adjacent to the aqueduct of Sylvius surface (Figure $2 a-c, f)$. At the most caudal levels, large $\mathrm{TH}+$ cells of the PAG disappeared and only periaqueductal PAG cells could be observed, together with small rounded neurons of the DR (Figure $2 \mathrm{~g}$ ). The estimate of the mean number of each cell type was: $1441.4 \pm 210$ small size cells of the RLi/vPAG, 129.4 \pm 31.3 large size cells of the PAG, and $305.8 \pm 43.5$ periaqueductal neurons of the PAG, as measured with the disector method. Numerous $\mathrm{TH}+$ fibers were detected running within the RLi/PAG region, mostly in the ventrolateral part of the PAG, with regularly spaced varicosities (Figure $2 \mathrm{~b}-\mathrm{d}$ ). In order to confirm that $\mathrm{TH}+$ cells were neurons, double immunofluorescent labelling of NeuN (neuronal marker) and $\mathrm{TH}$ was performed, indicating that all $\mathrm{TH}+$ cells were $\mathrm{NeuN}+$ (Figure $2 \mathrm{~h}, \mathrm{i})$. As shown in Figure $2 \mathrm{j}$, immunolabelling for $\mathrm{DBH}$, the noradrenaline synthesizing enzyme, indicated that no $\mathrm{DBH}+$ cells were observed in $\mathrm{RLi} / \mathrm{PAG}$, revealing that these neurons were dopaminergics. A control immunostaining study of the locus coeruleus (noradrenergic center) revealed that this nucleus contained $\mathrm{DBH}+$ cells as expected (data not shown).

\section{Experiment 2}

Dopamine neurons of the RLi/PAG, except periaqueductal $P A G$ cells, show enhanced $T H$ expression after repeated heroin treatment. Following a 3-day treatment with saline or $500 \mu \mathrm{g} / \mathrm{kg}$ heroin s.c., density measurement of TH signal revealed that $\mathrm{TH}+$ density of periaqueductal PAG neurons was not affected by heroin treatment, but a significant enhancement was observed in large PAG neurons $(U=2$, $p<0.01)$, and small RLi/vPAG dopamine neurons $(U=2.2$, $p<0.01$ ), as shown in Table 1 . This fact indicates that $\mathrm{TH}$ expression was induced in $\mathrm{TH}+$ neurons of the RLi/PAG region after repeated heroin treatment, except for periaqueductal ones. Western blotting also indicated that $\mathrm{TH}$ expression of the whole $\mathrm{RLi} / \mathrm{PAG}$ region was upregulated after 3-day treatment with heroin. Thus, density of blot bands was significantly enhanced in opiate-treated rats $v s$ lesioned animals $(p<0.01)$, as shown in Figure 3. No differences in the expression of PKA $\alpha$ were indicated by immunoblots. The immunoblot bands of $\alpha$-tubulin (control protein) indicated that similar amounts of protein were loaded.

\section{Experiment 3}

Dopamine depletion of the RLi/PAG region: morphology. After 6-OHDA infusions into the $\mathrm{RLi} / \mathrm{PAG}$ region, the number of large $\mathrm{TH}+\mathrm{PAG}$ cells and small RLi/vPAG neurons was reliably reduced by $61.9 \pm 3.4 \%$ (large PAG neurons, $t=3.5, p<0.01$ ) and $68.4 \pm 4 \%$ (RLi/vPAG neurons, $t=4.1, p<0.01$ vs sham normal), respectively, as observed in Figure $4 \mathrm{a}-\mathrm{e}$. Every lesioned rat presented a decreased number of these neurons higher than 55\% vs sham. The mean number of large PAG neurons was reduced from $306 \pm 43$ in sham rats to $49.3 \pm 10$ after lesion, and the number of RLi/vPAG neurons was reduced from $1442 \pm 210$ in sham rats to $455.5 \pm 34$ in lesioned animals. Periaqueductal neurons of the PAG were not affected by 6-OHDA injection. 6-OHDA solution did not diffuse into the more caudal DR (another component of the A10dc group) and nearby VTA, and dopamine cells of this latter region (strongly implicated in opiate reward) were not observed to be affected. Thus, total number of $\mathrm{TH}+$ cells in the VTA was $3848.6 \pm 125$ in sham animals and $3847.3 \pm 165$ cells in lesioned rats. For the DR, 225 \pm 21 and $215 \pm 18 \mathrm{TH}+$ neurons were counted in sham and lesioned animals, respectively.

'Anxiety-like' responses and locomotion. After 6-OHDA lesion of the RLi/PAG region, rats did not show emotional 

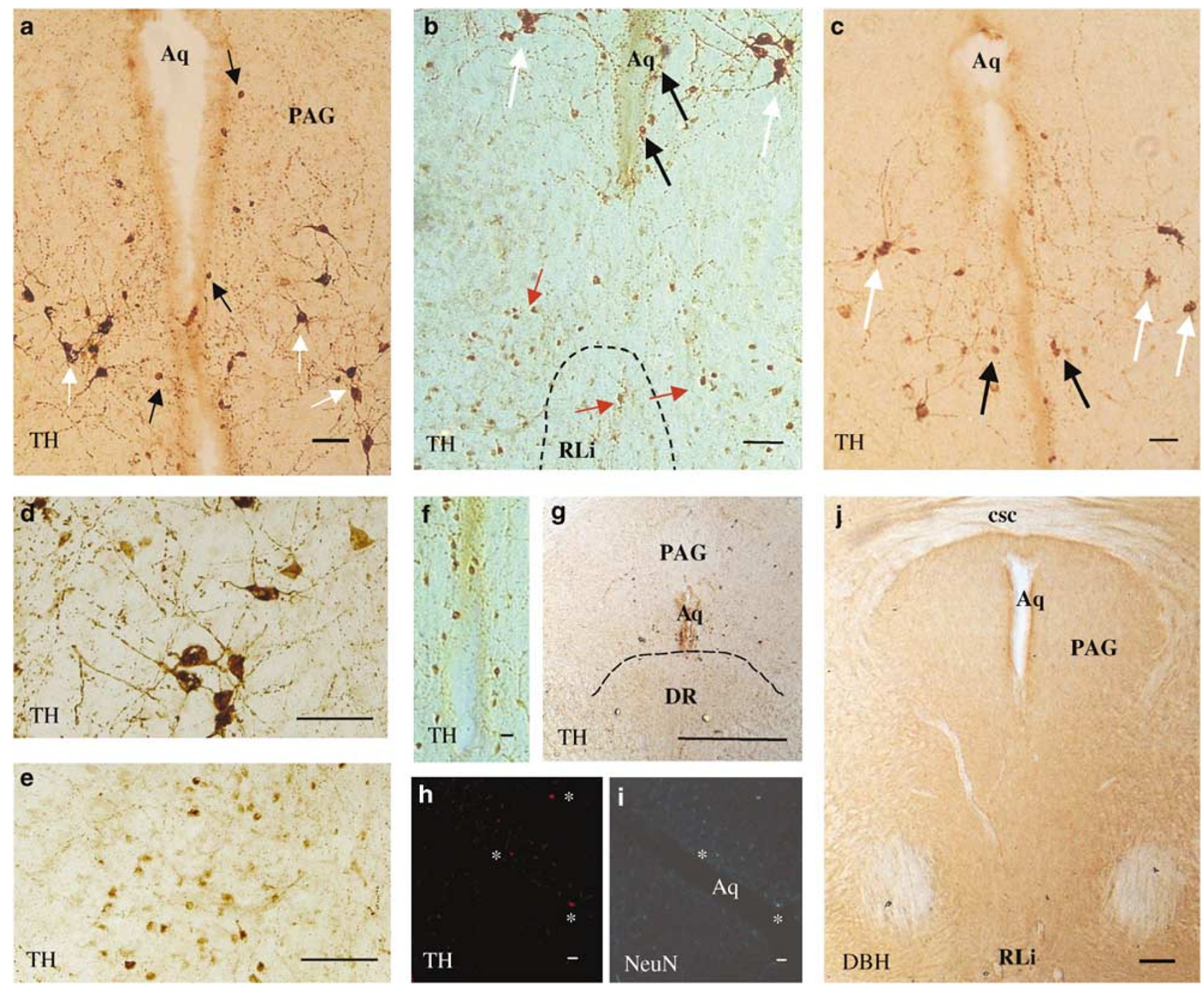

Figure 2 Morphological features of the dopaminergic RLi/PAG region. (a) Photomicrograph of the PAG region showing TH-positive large neurons located in the ventrolateral PAG (white arrows) and TH-positive periaqueductal PAG neurons (black arrow) surrounding the aqueduct of Sylvius (Aq). Section corresponding to bregma $-5.6 \mathrm{~mm}$ (Paxinos and Watson, 1997). (b) TH immunostained photomicrograph of the RLi/PAG region showing large-size neurons (white arrows), periaqueductal PAG neurons (black arrows), and TH-positive small Rli/PAG neurons (red arrows) scattered throughout both structures (the limit between PAG and RLi is drawn with a dashed line). (c) Another TH immunohistochemical picture showing large PAG neurons (white arrows), and periaqueductal PAG cells (black arrows). Higher magnification of large PAG cells (d) and small RLi/vPAG cells (e). Large PAG cells possess multipolar morphology and abundant arborization, with many $\mathrm{TH}+$ fibers with regularly spaced varicosities within the PAG. ( $f$ ) Higher magnification of TH + periaqueductal neurons, that are rounded neurons located adjacent to the aqueduct of Sylvius. (g) At the most caudal level of the PAG, only small TH + neurons of the PAG (and DR) can be observed. Section corresponding to bregma $-7.3 \mathrm{~mm}$ (Paxinos and Watson, 1997). Immunofluorescent photomicrographs of the PAG showing $\mathrm{TH}+$ cells ( $h$, red rhodamine positive cells) that are also immunoreactive to the neuronal marker NeuN (i), fluorescein positive cells) confirming that they are neurons (asterisks). (j) After immunostaining for DBH, no DBH + cells are observed in the whole RLi/PAG region. csc, commissure superior colliculi; Aq, aqueduct of Sylvius; RLi, rostral linear nucleus; PAG, periaqueductal gray; DR, dorsal raphe. Bars: I00 $\mu$ m, (f) $20 \mu \mathrm{m} ;(\mathrm{h}, \mathrm{i}) 200 \mu \mathrm{m}$.

'anxiety-like' disturbances, as revealed by no basal differences between sham and lesioned rats on 'anxiety-like' parameters, as shown in Table 2. Thus, in the light-dark test, time spent in the light compartment and number of transitions from dark to light (negative indicators of anxiety) were similar in both groups. In the elevated plusmaze tests, the time spent in open arms and the number of transitions to open arms (negative indicators of anxiety) were found to be similar in both groups. Following diazepam treatment, both groups of rats presented a similar anxiolytic profile (Table 2), and the anxiolytic effect of diazapem was evident by the significant increase in time spent in the light compartment in both groups $(t=3.2$, $p<0.05 v s$ saline-treated animals), along with the enhancement of percent time on open arms $(t=2.9, p<0.05 v s$ saline-treated). On the other hand, time in the dark compartment $(p<0.05)$ and percent time in closed arm $(p<0.01)$ were significantly reduced after diazepam in both sham and lesioned rats. Regarding basal locomotion, mean distance travelled $( \pm$ SEM) in the 10-min open-field test was found to be similar in both groups (sham, $58.5 \pm 6.2 \mathrm{~m}$; lesioned, $61.2 \pm 7.1 \mathrm{~m}$ ). 
Table I Density of TH+ Neurons of the RLi/PAG Region after Either Saline or Heroin Treatment

\begin{tabular}{lccc}
\hline Treatment & $\begin{array}{c}\text { RLi/vPAG } \\
\text { neurons }\end{array}$ & $\begin{array}{c}\text { Periaqueductal } \\
\text { PAG neurons }\end{array}$ & $\begin{array}{c}\text { Large PAG } \\
\text { neurons }\end{array}$ \\
\hline Saline & $56 \pm 8$ & $72 \pm 8$ & $45 \pm 9$ \\
Heroin & $77 \pm 7^{* * *}$ & $71.8 \pm 6.6$ & $78 \pm 7.7 * *$ \\
\hline
\end{tabular}

Values are expressed as percent mean \pm SEM with respect to a nondopaminergic background signal (commissure superior colliculi). Saline or heroin was administered daily during 3 days (heroin, $500 \mu g / \mathrm{kg} \mathrm{SC}$ ). *** $p 0.01$ vs corresponding neurons after saline. RLi, rostral linear nucleus; PAG, periaqueductal gray; vPAG, ventral PAG.

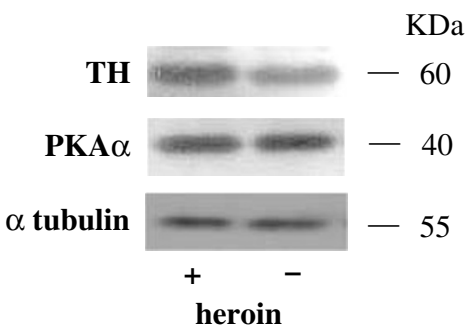

\begin{tabular}{lcc} 
& TH & PKA $\alpha$ \\
immunoreactivity & immunoreactivity \\
\hline heroin & $169 \pm 12 * *$ & $134 \pm 11$ \\
saline & $97 \pm 10$ & $148 \pm 12$
\end{tabular}

Figure 3 Top: Representative Western blots of two rats (+, treated with repeated heroin; -, treated with repeated saline) showing upregulation of TH expression, but not PKA $\alpha$, in the RLi/PAG region. $\alpha$-tubulin bands represent control protein bands (bands of both saline- and herointreated rats are similar). Bottom: Mean density values of blot bands in every heroin- or saline-treated rats. Values are expressed as percent mean + SEM with respect to background signal. Saline or heroin was administered daily during 3 days (heroin, $500 \mu \mathrm{g} / \mathrm{kg} \mathrm{SC}$ ). ${ }^{*} * p<0.0$ I vs saline.

Conditioned place preference. Habituation of conditioning during the second postconditioning test was not detected (data not shown). Three-way ANOVA revealed an interaction group $\times$ dose $\times$ compartment effect $(\mathrm{F}(1,28)=120.1$, $p<0.01)$ as well as a dose effect $(F(1,27)=98, p<0.05)$. Post-hoc analyses revealed that CPP developed in sham rats after $500 \mu \mathrm{g} / \mathrm{kg}$ heroin $(p<0.01 v s$ time spent in the salinepaired side), and place preference did not emerge in lesioned rats (Figure 5). Furthermore, sham rats spent significantly more times in the drug-paired side $(564 \pm 60 \mathrm{~s})$ than lesioned rats $(180 \pm 25 \mathrm{~s})$ during postconditioning, while both groups spent similar time in the saline-paired side. Finally, $100 \mu \mathrm{g} / \mathrm{kg}$ heroin did not induce place preference in either sham or lesioned rats, as shown in Figure 5.

Locomotor sensitization. Regarding heroin's motor sensitization, a group $\times$ dose $\times$ day interaction effect on distance travelled was revealed by ANOVA $(\mathrm{F}(5,140)=7.9, p<0.05)$. Significant group $\times$ dose $(F(1,27)=19.1, p<0.01)$ and dose effects $(F(5,140)=21, p<0.01)$ were also revealed by ANOVA. Post-hoc tests revealed that, after $50 \mu \mathrm{g} / \mathrm{kg}$ heroin, distance travelled was significantly enhanced in sham rats during the expression day (day 12$) v s$ day $1(p<0.05)$, as shown in Figure 5. No significant heroin's activating effects were observed in the lesioned group after $50 \mu \mathrm{g} / \mathrm{kg}$ heroin, and distance travelled by sham rats during day 12 was significantly higher than that travelled by lesioned animals $(p<0.05$; Figure 5). No significant heroin's activating effects were observed in both sham and lesioned groups following $100 \mu \mathrm{g} / \mathrm{kg}$ heroin. These data indicated that heroin's locomotor sensitization developed in sham rats, not in lesioned animals, after $50 \mu \mathrm{g} / \mathrm{kg}$ heroin, and that the highest heroin dose $(100 \mu \mathrm{g} / \mathrm{kg})$ was devoid of effects on locomotor sensitization.

\section{Experiment 4}

Systemic heroin and intra-RLi/PAG infusions of $D_{1}$ and $\mathrm{D}_{2}$ receptor antagonists. Two-way ANOVA indicated a significant dose $\times$ compartment effect on time spent in the heroin-paired side during postconditioning after intra-RLi/ PAG eticlopride, $D_{2}$ receptor antagonist $(F(2,21)=210$, $p<0.01$ ), but $\mathrm{SCH} 23390, \mathrm{D}_{1}$ receptor antagonist, was devoid of effects, as shown in Figure 6. Following every SCH23390 dose injection, mean time spent in the heroin-paired side was significantly higher than that in the saline-paired side during postconditioning, indicating the development of place preference $(p<0.01)$. However, these differences were affected by eticlopride infusions, as shown in Figure 6 . At $2.6 \mathrm{nmol}$ eticlopride, CPP remained $(p<0.05$ vs salinepaired side) although reduced with respect to 0 dose $(p<0.05 v s$ heroin-treated rats with local vehicle). Following $5.3 \mathrm{nmol}$ eticlopride, CPP was abolished and the time spent in the heroin-paired side was significantly reduced $v s 0$ dose $(p<0.01$ with respect to heroin-treated rats with local vehicle). The results hence indicate that intra-RLi/PAG infusions of eticlopride (but not $\mathrm{SCH} 23390$ ) reduced CPP in a dose-dependent manner. Injections of dopamine receptor antagonists in the vicinity of the RLi/PAG region (central tegmental tract) were devoid of effects on CPP (data not shown), further indicating that conditioned effects were not due to diffusion of dopaminergic antagonists into nearby structures.

\section{DISCUSSION}

There is a network of dopamine neurons extending throughout the mesencephalon and adjacent to the VTAA10 area, which includes the RLi, the PAG, and DR (Hökfelt et al, 1984; Peyron et al, 1995; Hasue and ShammahLagnado, 2002). The VTA is considered as a critical region for the rewarding and sensitizing properties of drugs of abuse, but in this study the role of extra-VTA dopamine regions (the RLi and PAG) on heroin reward and sensitization has been investigated. The findings indicate that the RLi/PAG dopamine network is involved in the rewarding and sensitizing properties of heroin.

The dopaminergic network of the RLi/PAG region is composed of three types of dopamine neurons: small RLi/ vPAG neurons, periaqueductal neurons of the PAG, and large-size PAG neurons, as reported by others (Hökfelt et al, 1976; Hasue and Shammah-Lagnado, 2002). NeuN labelling 

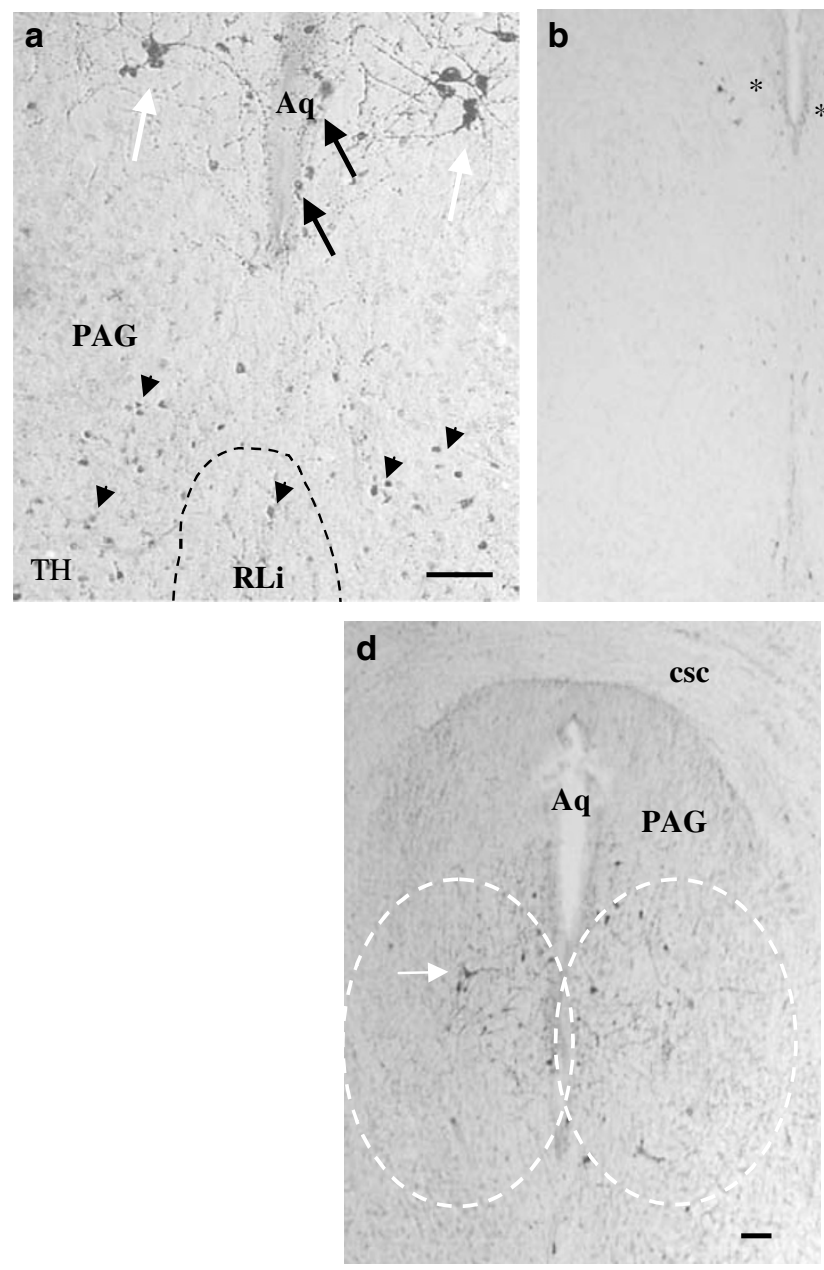
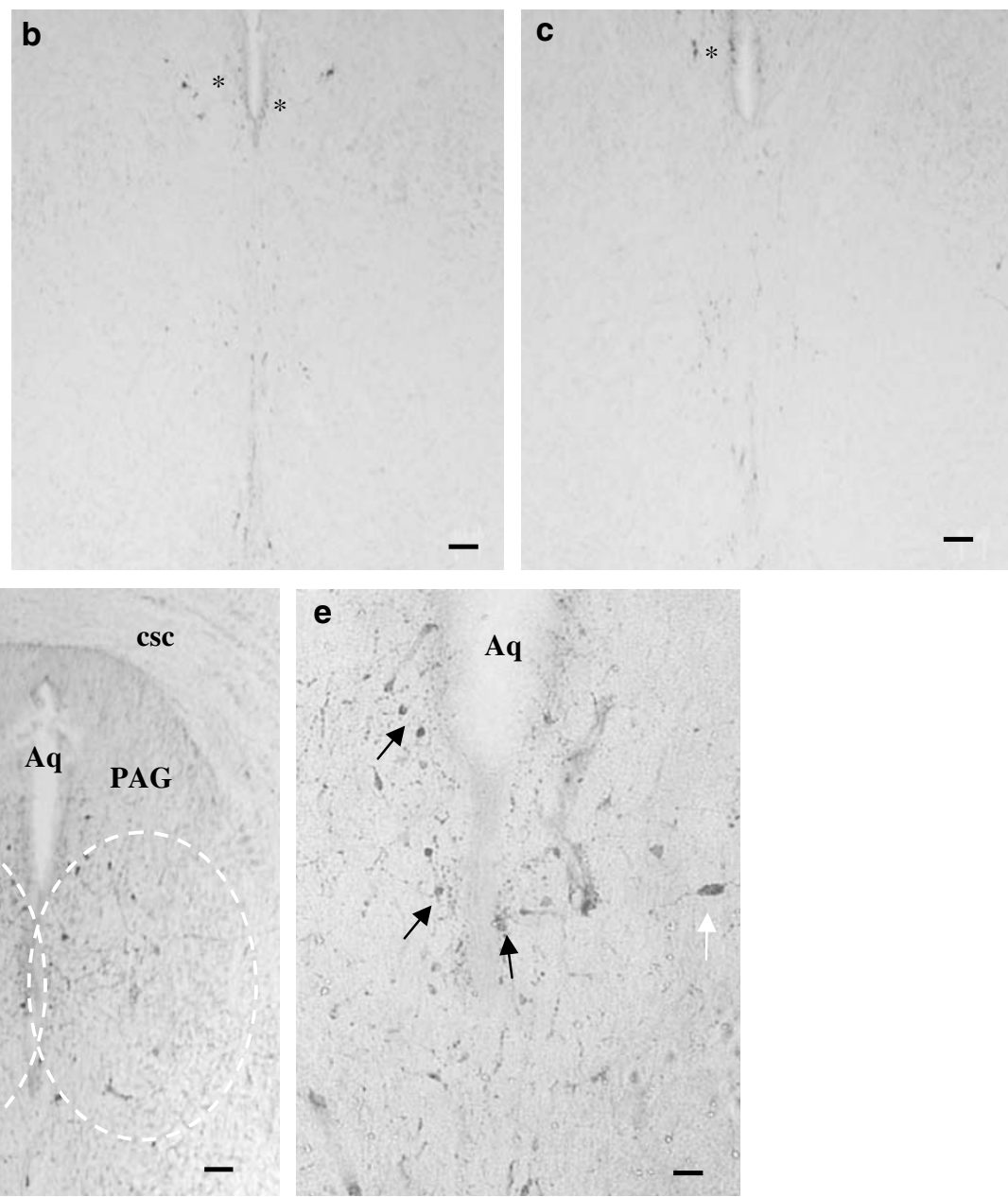

Figure 4 Morphological features of the 6-OHDA-lesioned RLi/PAG region, in comparison with normal RLi/PAG. (a) Comparative picture of a normal RLi/ PAG region with $\mathrm{TH}+$ neurons scattered throughout, comprising small RLi/vPAG neurons (black arrow heads), large neurons located in the ventrolateral PAG (white arrows), and periaqueductal PAG neurons (black arrows). The border between RLi and PAG is drawn with a dashed line. (b-d) Photomicrographs of RLi/PAG regions immunostained for TH from different animals, after 6-OHDA-induced lesion (same coronal level than in a). It can be observed that there is a clear scarcity of TH + neurons (compare with (a), and that lesion selectively affected large PAG neurons and small RLi/vPAG neurons (asterisks indicate the presence of periaqueductal neurons, and in (d) only one large neuron can be observed in the left PAG, as indicated with a white arrow). White dash line in (d) indicates the area of injection. (e) Higher magnification of a lesioned PAG region, where TH + periaqueductal neurons can be observed (black arrows) but the number of small and large TH + neurons are clearly reduced (only one large PAG neuron can be seen, white arrow). csc, commissure superior colliculi; Aq, aqueduct of Sylvius; RLi, rostral linear nucleus; PAG, periaqueductal gray. Bars: I00 $\mu$ m, except in (e), $50 \mu m$.

Table 2 Values of Behavioral Parameters in 'Anxiety-Like' Tests in Sham and 6-OHDA Lesioned Rats

Light dark test

\begin{tabular}{|c|c|c|c|c|c|c|c|}
\hline \multirow[b]{2}{*}{ Group } & \multirow[b]{2}{*}{ Treatment } & & \\
\hline & & $\begin{array}{l}\text { Time in } \\
\text { dark (s) }\end{array}$ & $\begin{array}{l}\text { Time in } \\
\text { light (s) }\end{array}$ & $\begin{array}{c}\text { Transitions } \\
\text { from dark to } \\
\text { light }\end{array}$ & $\begin{array}{l}\text { Percent } \\
\text { time on } \\
\text { open arm }\end{array}$ & $\begin{array}{l}\text { Percent } \\
\text { time in } \\
\text { closed arm }\end{array}$ & $\begin{array}{l}\text { Transitions } \\
\text { to open } \\
\text { arm }\end{array}$ \\
\hline & Diazepam & $212 \pm 20 *$ & $88 \pm 12 *$ & $1.2 \pm 0.5$ & $52.2 \pm 7 *$ & $39.4 \pm 10 * *$ & $10 \pm\left.\right|^{*}$ \\
\hline Lesioned & Saline & $253 \pm 21$ & $46 \pm 10$ & $1.5 \pm 0.6$ & $25 \pm 6.6$ & $75 \pm 7.3$ & $4 \pm 1.8$ \\
\hline
\end{tabular}

Mean \pm SEM. * $p<0.05, * * * 0.01$ vs corresponding saline group (Student's $t$-test). Both light-dark and elevated plus-maze tests lasted 5 min. Diazepam was administered at $2.5 \mathrm{mg} / \mathrm{kg}$ i.p., $30 \mathrm{~min}$ before test onset.

confirmed their neuronal phenotype. Abundant small dopamine cells $(10 \mu \mathrm{m}$ in diameter), with rounded morphology, are found scattered throughout the RLi and ventral
PAG, without a clear boundary between both structures because this dopaminergic network extends throughout both areas. Large PAG neurons (diameter $=30-50 \mu \mathrm{m}$ ) were 
a

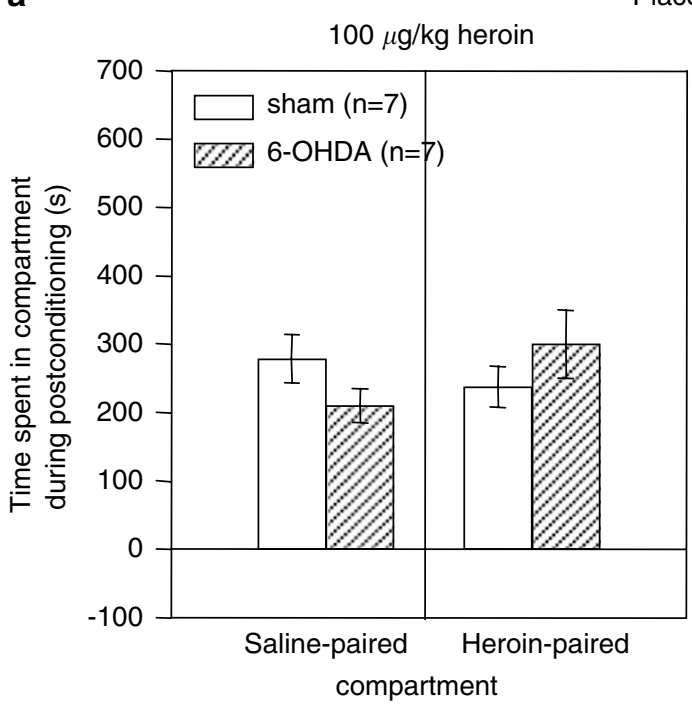

Place preference

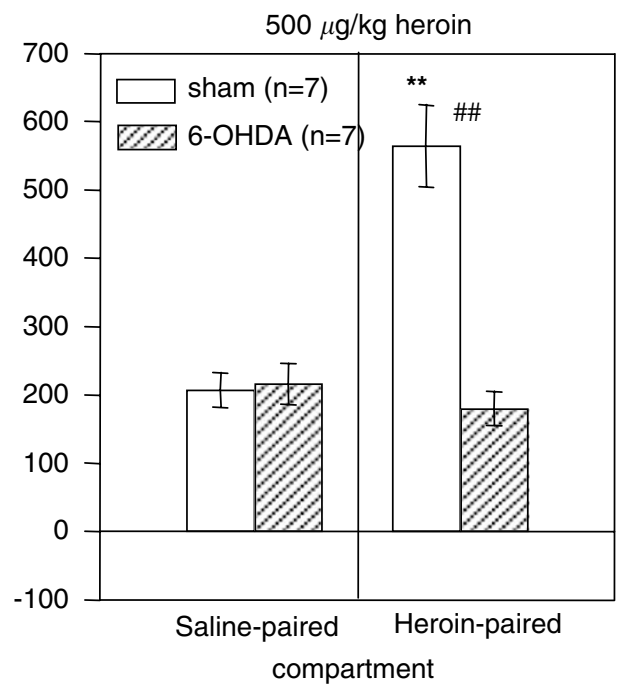

b

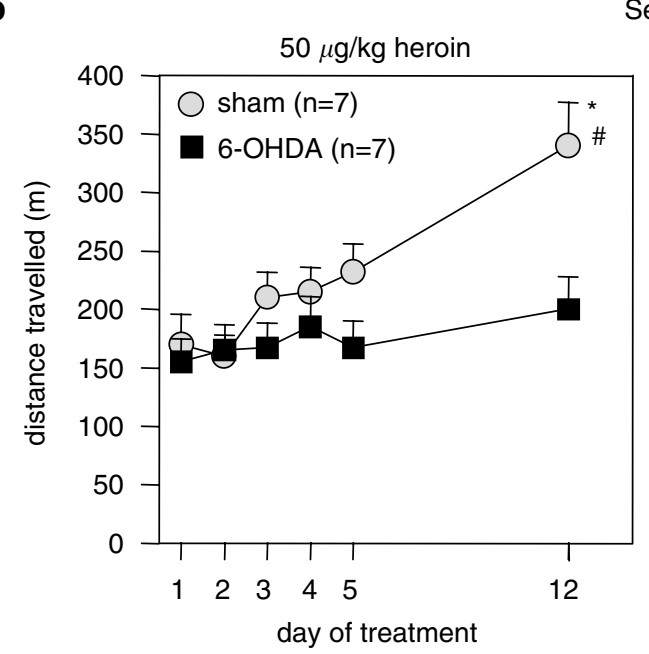

Sensitization

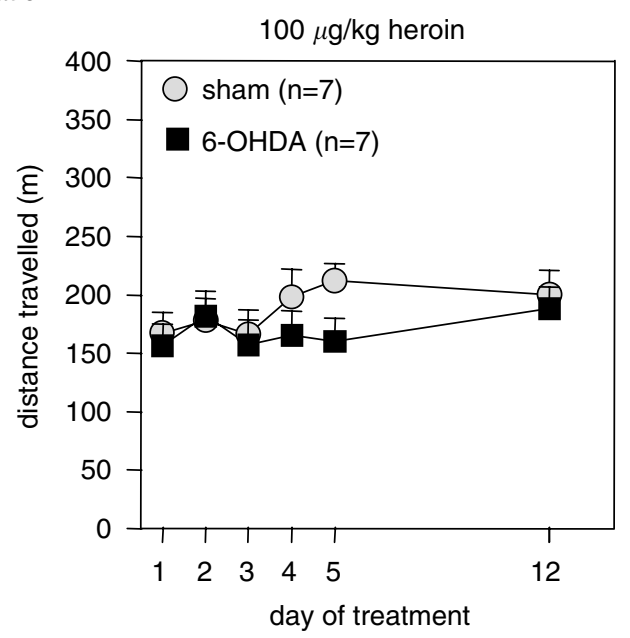

Figure 5 (a) CPP to heroin in 6-OHDA-lesioned and sham rats. It can be observed that CPP to $500 \mu g / k g$ heroin (right) was abolished by the lesion. The dose of $100 \mu \mathrm{g} / \mathrm{kg}$ heroin (left) was devoid of effects in CPP. Mean \pm SEM of time spent in each compartment during postconditioning, ** $<0.0$ I vs time spent by sham rats in saline-paired side; ${ }^{\# \#} p<0.0$ I vs time spent by lesioned rats in the heroin-paired side (Tukey's test). (b) Locomotor sensitization after repeated heroin treatment in 6-OHDA lesioned and sham rats. It can be observed that sham rats presented locomotor sensitization during the expression day (day 12) after $50 \mu \mathrm{g} / \mathrm{kg}$ heroin, but not lesioned animals. The dose of $100 \mu \mathrm{g} / \mathrm{kg}$ heroin was devoid of locomotor effects on both groups. Mean $\pm \mathrm{SEM}$, $* P<0.05$ vs day I of the same group; ${ }^{\#}<0.05$ vs lesioned rats during the same day (Tukey's test).

located in the ventrolateral PAG, and they are multipolar and present abundant arborization. Periaqueductal PAG cells $(15 \mu \mathrm{m}$ in diameter) possess a rounded morphology, and they are mostly located adjacent to the aqueduct of Sylvius. At the most caudal levels of the PAG, large dopamine neurons disappear, and only small dopamine cells can be observed, now including those of the DR, another component of the A10dc group. Many TH + fibers are seen running within the ventrolateral PAG in accordance with Peyron et al (1995), with regularly spaced synaptic varicosities resembling those observed in other dopaminergic areas such as dorsal striatum, suggesting the existence of a local circuit controlled by dopaminergic neurons. In this context, previous studies have described the presence of scattered dopaminergic neurons in the PAG with relatively short axons, along with larger $\mathrm{TH}+$ fibers projecting to different structures such as central amygdaloid nucleus and extended amygdala (Hökfelt et al, 1976; Grove, 1988; Hasue and Shammah-Lagnado, 2002). The presence of synaptic varicosities in the PAG has also been described (Buma et al, 1992).

Repeated heroin induced enhanced levels of TH (the ratelimiting enzyme in dopamine synthesis) in $\mathrm{RLi} / \mathrm{vPAG}$ neurons and large PAG neurons, without changes in the expression of $\mathrm{PKA} \alpha$, as measured through TH-ir densitometry and blotting. TH enhancement could also be accounted for by upregulation of this enzyme in other cathecolaminergic neurons (noradrenergic and adrenergic, both $\mathrm{TH}+$ and $\mathrm{DBH}+$ ), but $\mathrm{DBH}$ immunohistochemistry discarded the presence of these cathecolaminergic neurons in the RLi/PAG region. Repeated opiate drug exposure is known to induce biochemical changes in specific brain 
a

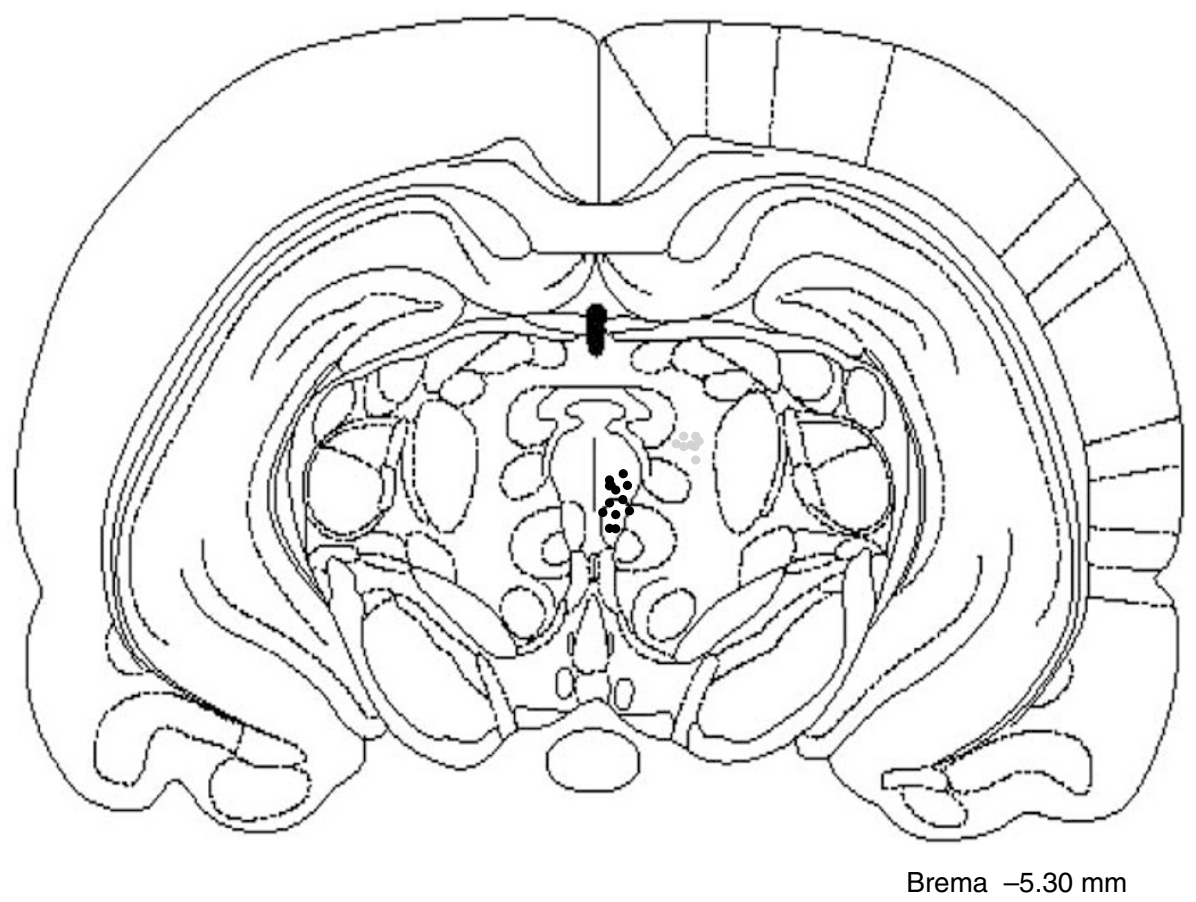

b

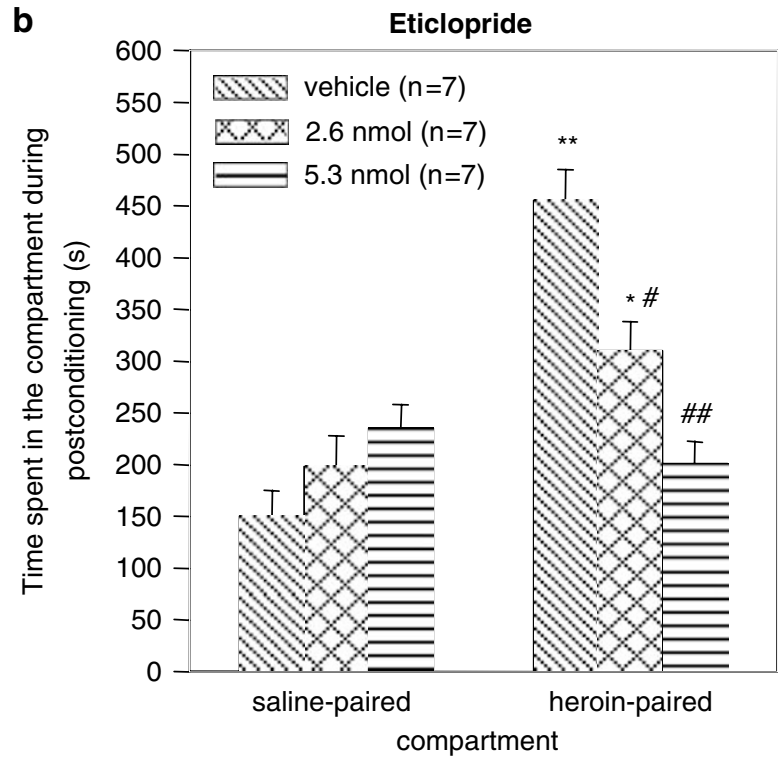

SCH23390

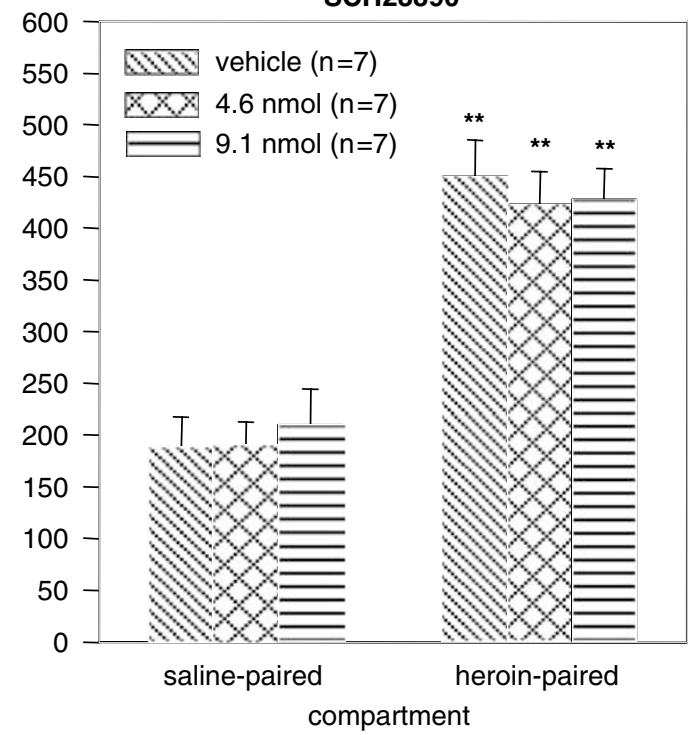

Figure 6 (a) Locations of infusions into the RLi/vPAG in rats that received local injections of dopaminergic antagonists (black dots), as well infusion sites outside the RLi/PAG (central tegmental tract, gray dots). (b) CPP to $500 \mu \mathrm{g} / \mathrm{kg}$ heroin after intra-RLi/vPAG injections of vehicle, eticlopride $\left(\mathrm{D}_{2}\right.$ dopamine receptor antagonist), and SCH23390 ( $\mathrm{D}$, dopamine receptor antagonist). Mean \pm SEM of time spent in each compartment during postconditioning. ${ }^{*} p<0.05,{ }^{*} * 0<0.01$ vs corresponding value in the saline-paired compartment; ${ }^{\#} p<0.05,{ }^{\# \#} p<0.0$ I vs time spent in the heroin-paired compartment after intra-RLi/PAG vehicle (Tukey's test).

regions thought to mediate the reinforcing actions of drugs, mostly the mesolimbic dopamine system (Wise, 1989; Nestler and Aghajanian, 1997; Nestler, 2001). Thus, repeated opiate exposure increases VTA TH levels as well as glutamate receptor subunits such as NMDAR1 during the induction phase of sensitization (Beitner-Johnson and Nestler, 1991; Self et al, 1995; Fitzgerald et al, 1996; Shippenberg and Elmer, 1998; Brodkin et al, 1999). In the nucleus accumbens, chronic opiate treatment is known to up-regulate activity of the cAMP pathway, increasing levels of PKA $\alpha$ (Terwilliger et al, 1991). The present study reveals that there are also adaptive biochemical changes in the RLi/ PAG region after a repeated exposure to heroin (3-days), as revealed by TH upregulation, without changes in PKA $\alpha$ expression. These findings are quite similar to those found in the nearby VTA after chronic opiate treatment (BeitnerJohnson and Nestler, 1991). Considering that PKA $\alpha$ levels were not enhanced after heroin, TH upregulation appears 
not to be due to activation of the cAMP pathway. TH expression could be upregulated by increase of $\mathrm{Ca}^{2+}$ entry into dopamine VTA neurons, that activate enzymes such as calcium-calmodulin-dependent-kinase II (CaMKII), or after activation of other kinases such as protein kinase C (Self and Nestler, 1995; Williams et al, 2001). Post-transcriptional mechanisms based on regulation of $\mathrm{TH}$ mRNA stability have also been proposed for explaining $\mathrm{TH}$ upregulation after opiates (Kumer and Vrana, 1996; Boundy et al, 1998). These facts deserve further investigation.

After 6-OHDA-induced lesion, this neurotoxin affected every dopamine RLi/PAG neuron except for periaqueductal neurons, indicating that either the toxin did not diffuse into the periaqueductal region (that is unlikely considering the injection area, and the fact that neighboring large $\mathrm{TH}+$ neurons were deeply affected) or there is a differential vulnerability to this toxin in $\mathrm{TH}+$ cells of the PAG. This latter hypothesis is in line with the fact that dopaminergic neurons of the DR (another part of the A10dc area as mentioned) are known to display a differential vulnerability to toxic agents, as reported by Unguez and Schneider (1988), who noted a more extensive $\mathrm{TH}+$ cell loss in the ventral part of the DR than in the dorsal part in MPTPtreated monkeys. These findings are otherwise consistent with the suggestion that dopamine periaqueductal cells are extensions of the periventricular system (Lindvall et al, 1974; Lindvall and Björklund, 1974; Moore and Bloom, 1978), which lacks the dopamine transporter DAT and is immune to 6-OHDA, whereas the remainder $\mathrm{RLi} / \mathrm{PAG}$ neurons are extensions of the VTA (Hasue and ShammahLagnado, 2002), which expresses DAT and hence is vulnerable to the toxin (Kilty et al, 1991; Shimada et al, 1992; Fujita et al, 1993). In this context, the RLi nucleus is considered as a part of the VTA by some authors (Oades and Halliday, 1987). The neurotoxic effect of 6-OHDA was restricted to the $\mathrm{RLi} / \mathrm{PAG}$ region because the VTA and DR areas were not affected, further reinforcing that observed functional effects were caused by the selective disruption of the dopaminergic network of the RLi/PAG region.

Regarding these functional effects, 6-OHDA infusions into the $\mathrm{RLi} / \mathrm{PAG}$ region did not alter basal locomotion and 'anxiety-like' responses, discarding that possible motor or emotional deficits after lesion could mask or interfere functional results in heroin-treated lesioned rats. However, dopamine neurons of the $\mathrm{RLi} / \mathrm{PAG}$ region appear to mediate heroin-induced reward critically because CPP to $500 \mu \mathrm{g} / \mathrm{kg}$ heroin was abolished following dopaminergic lesion of the $\mathrm{RLi} / \mathrm{PAG}$ region. CPP is widely used for discerning positive incentive-motivational effects of drugs of abuse, and it is a Pavlovian test based on the conditioned association between certain environment and the incentive actions of the drug (Koob et al, 1986; Bardo et al, 1995; Tzschentke, 1998). The incentive value of heroin, an important factor for the development of addiction (Robinson and Berridge, 1993; Nestler, 2001), can thus be estimated through this test. On the other hand, the data suggest that $\mathrm{D}_{2}$ dopamine receptors (but not $\mathrm{D}_{1}$ ) within $\mathrm{RLi} / \mathrm{PAG}$ seem to participate in the rewarding effects of heroin, since their blockade with eticlopride (a very selective $\mathrm{D}_{2}$ antagonist; Seeman and Van Tol, 1994) reduced CPP to heroin in a dose-dependent manner. $\mathrm{D}_{2}$ dopamine receptors are known to be expressed by PAG neurons (Bouthenet et al, 1987; Martin-Ruiz et al,
2001), but the presence and distribution of $D_{1}$ dopamine receptor in neurons of $\mathrm{RLi} / \mathrm{PAG}$ has not been described so far. The present study indicates that a population of RLi/ PAG neurons expressing $\mathrm{D}_{2}$ dopamine receptors are involved in the modulation of heroin's rewarding effects. The mechanism of action of eticlopride is difficult to explain. Considering that $\mathrm{D}_{2}$ receptors expressed by midbrain DA neurons (substantia nigra and VTA) are mostly inhibitory autoreceptors located on dendrites and perikarya (Bouthenet et al, 1987), and assuming a similar localization in the RLi/PAG (extra-VTA extension), eticlopride would be expected to enhance dopaminergic release, hence facilitating dopaminergic activity within the RLi/PAG region. In this case, functional effects should be opposite to those observed following RLi/PAG dopamine lesion. However, these receptors could be also heteroceptors located on nondopaminergic neurons, and $\mathrm{D}_{2}$-mediated effects could be indirect through a modification of other neurotransmitter systems such as the midbrain serotonergic one. Thus, it is known that dopamine depolarizes midbrain serotonin neurons by an action on $\mathrm{DA} \mathrm{D}_{2}$ receptors (Haj-Dahmane and Shen, 2000), and systemic quinpirole ( $\mathrm{D}_{2}$ agonist) enhances serotonin release in the DR (Martin-Ruiz et al, 2001), and it has been proposed that DA $D_{2}$ receptors outside the DR (likely on PAG GABA neurons) control serotonergic activity in this nucleus (Martin-Ruiz et al, 2001). Furthermore, DR serotonin neurotransmission is involved in CPP, because local infusions of the $5-\mathrm{HT}_{1}$ agonist 8-OH-DPAT into the DR produce CPP (Fletcher et al, 1993). It can be hypothesized that an eticlopridemediated indirect inhibition of serotonin neurons of the DR could disrupt CPP to heroin. It must be taken into account that infusions of dopaminergic antagonists were made unilaterally, and it is likely that the effects would become more robust if injections were made bilaterally.

Heroin's locomotor sensitization was blocked after dopamine depletion within the $\mathrm{RLi} / \mathrm{PAG}$ region, at the $50 \mu \mathrm{g} / \mathrm{kg}$ heroin dose. A higher dose $(100 \mu \mathrm{g} / \mathrm{kg})$ was devoid of effect on sensitization, which could be accounted for by the emergence of sedative effects of the opiate drug. This fact is otherwise in accordance with previous findings indicating that locomotor sensitization is better discerned following repeated low heroin doses $(<100 \mu \mathrm{g} / \mathrm{kg})$, because higher doses are known to induce hypolocomotion and catalepsy (Marinelli et al, 1998; Pontieri et al, 2001). Locomotor sensitization is the enduring enhancement in the motor stimulant effects elicited by repeated drug administration (Stewart and Badiani, 1993; Vanderschuren and Kalivas, 2000; Nestler, 2001), and neural adaptations that result in sensitization in animal models are likely the same that result in some forms of addictive behavior in humans (Robinson and Berridge, 1993; Carlezon et al, 1997; Nestler and Aghajanian, 1997; Nestler, 2001). Locomotor sensitization has been hypothesized to be a manifestation of enhanced motivational ('wanting') properties of drugs, or of the neural adaptations underlying drug craving (Robinson and Berridge, 1993). The dopaminergic network of the $\mathrm{RLi} / \mathrm{PAG}$ region hence seems to be involved in the development or induction of locomotor sensitization to opiates.

As explained before, dopamine neurons of the RLi and PAG project onto structures such as central amygdaloid 
nucleus, bed nucleus of the stria terminalis, sublenticular extended amygdala, and substantia innominata (Ottersen, 1981; Grove, 1988; Hasue and Shammah-Lagnado, 2002). Dopaminergic activity in some of these areas has been reported to be involved in rewarding and sensitizing properties of drugs of abuse such as opiates (Wise, 1989; Caine et al, 1995; Di Chiara et al, 1999; Nestler, 2001). The data of the present study suggest that the dopaminergic network of the RLi/PAG region would also participate in these processes. Besides, considering a possible dopamine/ serotonin interaction for explaining the effect of eticlopride on CPP, a link between the RLi/PAG region and serotonergic DR activity on opiate reward cannot be ruled out. To sum up, it seems that dopaminergic areas adjacent to the VTA such as RLi and PAG play a similar role as that of the VTA in the induction of opiate sensitization and reward. In this respect, Hasue and Shammah-Lagnado (2002) have proposed that, since RLi, and PAG TH + afferents course in the VTA and medial forebrain bundle to innervate the amygdala (Vertes, 1991), the substantial decrease in amygdala dopamine content produced by VTA lesions should be ascribed to interruption of both A10, RLi and A10dc amygdalopetal projections. The fact that CPP was blocked after lesion of the RLi/PAG region while VTA remained intact suggests that the mesencephalic dopamine network (including VTA and RLi/PAG) acts as an integrated neural system whose disruption exerts a profound effect on heroin effects. To sum up, the RLi/PAG region should be included as another critical dopaminergic region for the induction of heroin's sensitization and reward, apart from the VTA. $\mathrm{D}_{2}$ dopamine receptors located on neurons of the $\mathrm{RLi} / \mathrm{PAG}$ region seem to participate in heroin's reward effects.

\section{ACKNOWLEDGEMENTS}

This study was supported by FIS (PI040155) to EFE, Plan Nacional sobre drogas, Plan Andawz de Investigacion (PAI CVI127), and Red de trastornos adictivos (G03/05, Instituto Carlos III). We thank Dr Ana I Rojo (Madrid, Spain) for her help in blotting procedures.

\section{REFERENCES}

Bardo MT, Rowlett JK, Harris MJ (1995). Conditioned place preference using opiate and stimulant drugs: a meta-analysis. Neurosci Biobehav Rev 19: 39-51.

Beitner-Johnson D, Nestler EJ (1991). Morphine and cocaine exert common chronic actions on tyrosine hydroxylase in dopaminergic brain reward regions. J Neurochem 57: 344-347.

Boundy VA, Gold SJ, Messer CJ, Chen J, Son JH, Joh TH et al (1998). Regulation of tyrosine hydroxylase promoter activity by chronic morphine in TH9.0-LacZ transgenic mice. J Neurosci 18: 9989-9995.

Bouthenet ML, Martres MP, Sales N, Schwartz JC (1987). A detailed mapping of dopamine D-2 receptors in rat central nervous system by autoradiography with [125I]iodosulpride. Neuroscience 20: 117-155.

Brodkin ES, Kosten TA, Haile CN, Heninger GR, Carlezon Jr WA, Jatlow P et al (1999). Dark Agouti and Fischer 344 rats: differential behavioral responses to morphine and biochemical differences in the ventral tegmental area. Neuroscience 88: 1307-1315.
Buma P, Veening J, Hafmans T, Joosten H, Nieuwenhuys R (1992). Ultrastructure of the periaqueductal grey matter of the rat: an electron microscopical and horseradish peroxidase study. J Comp Neurol 319: 519-535.

Caillé S, Espejo EF, Reneric JP, Cador M, Koob GF, Stinus L (1999). Total neurochemical lesion of noradrenergic neurons of the locus coeruleus does not alter either naloxone-precipitated or spontaneous opiate withdrawal nor does it influence ability of clonidine to reverse opiate withdrawal. J Pharmacol Exp Therap 290: 881-892.

Caine SB, Heinrichs SC, Coffin VL, Koob GF (1995). Effects of the dopamine D-1 antagonist SCH-23390 microinjected into the accumbens, amygdala or striatum on cocaine self-administration in the rat. Brain Res 692: 47-56.

Carlezon WA, Boundy VA, Haile CN, Lane SB, Kalb RG, Neve RL et al (1997). Sensitization to morphine induced by viralmediated gene transfer. Science 277: 812-814.

Cunningham ST, Kelley AE (1993). Hyperactivity and sensitization to psychostimulants following cholera toxin infusion into the nucleus accumbens. J Neurosci 13: 2342-2350.

Di Chiara G, Tanda G, Bassareo V, Pontieri F, Acquas E, Fenu S et al (1999). Drug addiction as a disorder of associative learning: role of nucleus accumbens shell/extended amygdala. In: McGinty $\mathrm{J}$ (ed). Advancing from the Ventral Striatum to the Extended Amygdala: Implications for Neuropsychiatry and Drug Abuse (Series: Annals of the New York Academy of Sciences, Vol 877), Annals New York Academy of Sciences: New York. pp 461-485.

Espejo EF (1997). Selective dopamine depletion within the medial prefrontal cortex induces anxiogenic-like effects in rats placed on the elevated plus-maze. Brain Res 762: 281-284.

Espejo EF, Miñano J (1999). Prefrontocortical dopamine depletion induces antidepressant-like effects in rats, and alters the profile of desipramine during Porsolt's test. Neuroscience 88: 609-615.

Finlay JM, Zigmond MJ, Abercrombie ED (1995). Increased dopamine and norepinephrine release in medial prefrontal cortex induced by acute and chronic stress: effects of diazepam. Neuroscience 64: 619-628.

Fitzgerald LW, Ortiz J, Hamedani AG, Nestler EJ (1996). Drugs of abuse and stress increase the expression of GluR1 and NMDAR1 glutamate receptor subunits in the rat ventral tegmental area: common adaptations among cross-sensitizing agents. J Neurosci 16: $274-282$.

Fletcher PJ, Ming ZH, Higgins GA (1993). Conditioned place preference induced by microinjection of $8-\mathrm{OH}-\mathrm{DPAT}$ into the dorsal or median raphe nucleus. Psychopharmacology (Berl) 113: 31-36.

Fujita M, Shimada S, Nishimura T, Uhl GR, Tohyama M (1993). Ontogeny of dopamine transporter mRNA expression in the rat brain. Brain Res Mol Brain Res 19: 222-226.

Grove EA (1988). Neural associations of the substantia innominata in the rat: afferent connections. J Comp Neurol 277: 315-346.

Gundersen HJG, Jensen EB (1987). The efficiency of systematic sampling in stereology and its prediction. J Microsc 147: 229-263.

Haj-Dahmane S, Shen RY (2000). Dopamine D2-like receptor activation depolarizes rat dorsal raphe serotonin neurons. Soc Neurosci Abs 26: 1419.

Hasue RH, Shammah-Lagnado SJ (2002). Origin of the dopaminergic innervation of the central extended amygdala and accumbens shell: a combined retrograde tracing and immunohistochemical study in the rat. J Comp Neurol 454: 15-33.

Hökfelt T, Johansson O, Fuxe K, Goldstein M, Park D (1976). Immunohistochemical studies on the localization and distribution of monoamine neuron systems in the rat brain. I. Tyrosine hydroxylase in the mes- and diencephalon. Med Biol 54: 427-453.

Hökfelt T, Martensson R, Björklund A, Kleinau S, Goldstein M (1984). Distributional maps of tyrosine-hydroxylase-immuno- 
reactive neurons in the rat brain. In: Björklund A, Hökfelt $\mathrm{T}$ (eds). Classical Transmitters in the CNS (Series Handbook of Chemical Neuroanatomy, Vol 2). Elsevier: Amsterdam. pp 277-379.

Kilty JE, Lorang D, Amara SG (1991). Cloning and expression of cocaine-sensitive rat dopamine transporter. Science 254: 578-579.

Koob GF, Vaccarino FJ, Amalric M, Bloom FE (1986). Neurochemical substrates for opiate reinforcement. NIDA Res Monogr 71: 146-164.

Kumer SC, Vrana KE (1996). Intrincate regulation of tyrosine hydroxylase activity and gene expression. J Neurochem 67: 443-462.

Lagares A, Avendaño C (1999). An efficient method to estimate cell number and volume in multiple dorsal root ganglia. Acta Stereol 18: 185-195.

Lindvall O, Björklund A (1974). The organization of the ascending catecholamine neuron systems in the rat brain as revealed by the glyoxilic acid fluorescence method. Acta Physiol Scand Suppl 412: 1-48.

Lindvall O, Björklund A, Moore RY, Stenevi U (1974). Mesencephalic dopamine neurons projecting to neocortex. Brain Res 81: 325-331.

Marinelli M, Le Moal M, Piazza PV (1998). Sensitization to the motor effects of contingent infusions of heroin but not of kappa agonist RU 51599. Psychopharmacology 139: 281-285.

Martin-Ruiz R, Ugedo L, Honrubia MA, Mengod G, Artigas F (2001). Control of serotonergic neurons in rat brain by dopaminergic receptors outside the dorsal raphe nucleus. J Neurochem 77: 762-775.

Messer CJ, Eisch AJ, Carlezon WA, Whisler K, Shen L, Wolf DH et al (2000). Role for GDNF in biochemical and behavioral adaptations to drugs of abuse. Neuron 26: 247-257.

Miserendino MJ, Nestler EJ (1995). Behavioral sensitization to cocaine: modulation by the cyclic AMP system in the nucleus accumbens. Brain Res 674: 299-306.

Moore RY, Bloom FE (1978). Central catecholamine neuron systems: anatomy and physiology of the dopamine systems. Ann Rev Neurosci 1: 129-169.

Nestler EJ (2001). Molecular basis of long-term plasticity underlying addiction. Nat Rev Neurosci 2: 119-128.

Nestler EJ, Aghajanian GK (1997). Molecular and cellular basis of addiction. Science 278: 58-63.

Nye HE, Nestler EJ (1996). Induction of chronic Fos-related antigens in rat brain by chronic morphine administration. Mol Pharmacol 49: 636-645.

Oades RD, Halliday GM (1987). Ventral tegmental (A10) system: neurobiology. I. Anatomy and connectivity. Brain Res Rev 12: $117-165$.

Ottersen OP (1981). Afferent connections to the amygdaloid complex of the rat with some observations in the cat. III. Afferents from the lower brainstem. I Comp Neurol 202: 335-356.

Paxinos G, Watson C (1997). The Rat Brain in Stereotaxic Coordinates. Academic Press: Sydney.

Peyron C, Luppi PH, Kitahama K, Fort P, Hermann DM, Jouvet M (1995). Origin of the dopaminergic innervation of the rat dorsal raphe nucleus. Neuroreport 6: 2527-2531.

Phillipson OT (1979). The cytoarchitecture of the interfascicular nucleus and ventral tegmental area of Tsai in the rat. J Comp Neurol 187: 85-98.

Pontieri FE, Monnazzi P, Scontrini A, Buttarelli FR, Patacchioli FR (2001). Behavioral sensitization to heroin by cannabinoid pretreatment in the rat. Eur J Pharmacol 421: R1-R3.
Robinson TE, Berridge KC (1993). The neural basis of drug craving: an incentive-sensitization theory of addiction. Brain Res Rev 18: 247-291.

Rodgers RJ, Cole JC (1994). The elevated plus-maze: pharmacology, methodology and ethology. In: Cooper SJ, Hendrie CA (eds). Ethology and Psychopharmacology. Wiley: New York. pp 9-44.

Schulteis G, Markou A, Gold LH, Stinus L, Koob GF (1994). Relative sensitivity to naloxone of multiple indices of opiate withdrawal: a quantitative dose-response analysis. J Pharmacol Exp Ther 271: 1391-1398.

Seeman P, Van Tol HH (1994). Dopamine receptor pharmacology. Trends Pharmacol Sci 15: 264-270.

Segal DS, Kuczenski R (1992). Repeated cocaine administration induces behavioral sensitization and corresponding decreased extracellular dopamine responses in caudate and accumbens. Brain Res 577: 351-355.

Self DW, McClenahan AW, Beitner-Johnson D, Terwilliger RZ, Nestler EJ (1995). Biochemical adaptations in the mesolimbic dopamine system in response to heroin self-administration. Synapse 21: 312-318.

Self DW, Nestler EJ (1995). Molecular mechanisms of drug reinforcement and addiction. Annu Rev Neurosci 18: 463-495.

Shimada S, Kitayama S, Walther D, Uhl G (1992). Dopamine transporter mRNA: dense expression in ventral midbrain neurons. Brain Res Mol Brain Res 13: 359-362.

Shippenberg TS, Elmer GI (1998). The neurobiology of opiate reinforcement. Crit Rev Neurobiol 12: 267-303.

Sklair-Tavron L, Shi WX, Lane SB, Harris HW, Bunney BS, Nestler EJ (1996). Chronic morphine induces visible changes in the morphology of mesolimbic dopamine neurons. Proc Natl Acad Sci USA 93: 11202-11207.

Sterio DC (1984). The unbiased estimation of number and sizes of arbitrary particles using the disector. J Microsc 134: 127-136.

Stewart J, Badiani A (1993). Tolerance and sensitization to the behavioral effects of drugs. Behav Pharmacol 4: 289-312.

Stinus L, Le Moal M, Koob GF (1990). Nucleus accumbens and amygdala are possible substrates for the aversive stimulus effects of opiate withdrawal. Neuroscience 37: 767-773.

Terwilliger RZ, Beitner-Johnson D, Sevarino KA, Crain SM, Nestler EJ (1991). A general role for adaptations in G-proteins and the cyclic AMP system in mediating the chronic actions of morphine and cocaine on neuronal function. Brain Res 548: 100-110.

Tzschentke TM (1998). Measuring reward with the conditioned place preference paradigm: a comprehensive review of drug effects, recent progress and new issues. Prog Neurobiol 56: 613-672.

Unguez GA, Schneider JS (1988). Dopaminergic dorsal raphe nucleus in cats and monkeys are sensitive to the toxic effects of MPTP. Neurosci Lett 94: 218-223.

Vanderschuren LJMJ, Kalivas PW (2000). Alterations in dopaminergic and glutamatergic transmission in the induction and expression of behavioral sensitization: a critical review of preclinical studies. Psychopharmacology 151: 99-120.

Vertes RP (1991). A PHA-L analysis of ascending projections of the dorsal raphe nucleus in the rat. J Comp Neurol 313: 643-668.

Williams JT, Christie MJ, Manzoni O (2001). Cellular and synaptic adaptations mediating opioid dependence. Physiol Rev 81: 299-343.

Wilson MA, Burghardt PR, Ford KA, Wilkinson MB, Primeaux SD (2004). Anxiolytic effects of diazepam and ethanol in two behavioral models: comparison of males and females. Pharmacol Biochem Behav 78: 445-458.

Wise RA (1989). Opiate reward: sites and substrates. Neurosci Biobehav Rev 13: 29-133. 